\title{
Os Cursos Técnicos da Educação a Distância (EAD): uma Análise dos Perfis dos Alunos Ingressos do Nordeste Brasileiro
}

\author{
Adelito Farias $^{1}$, Mariana Pereira ${ }^{2}$, Simone Oliveira $^{3}$, Sérgio Galdino ${ }^{1}$ \\ ${ }^{1}$ Escola Politécnica de Pernambuco - Universidade de Pernambuco (UPE) \\ ${ }^{2}$ Centro de Estudos e Sistemas Avançados do Recife (CESAR) \\ ${ }^{3}$ Universidade Federal Rural de Pernambuco (UFRPE) \\ abf@ecomp.poli.br, mpx@cesar.org.br, moneolivier2@gmail.com, \\ sergio.galdinolieee.org
}

\begin{abstract}
Brazilian Government has been creating programs that encourage continuity in professional training. The program e-Tec Network, has the mission to provide technical courses in the distance to the Metropolitan peripheries and isolated locations of major centers. This work was built with the purpose of understanding the profile of students tickets in these courses, analyze the student's vision as the didactic structure available and expectations at the end of the course. Among the results, is believed that the program is achieving good results, but there are pedagogical solutions that can be developed and adopted to mitigate the deficits in the quality of training received by future students of this project.
\end{abstract}

Resumo. O Governo Brasileiro vem criando programas que incentivam a continuidade da capacitação profissional. O programa Rede e-Tec, possui a missão de dispor cursos técnicos na modalidade de educação a distância para as localidades isoladas dos grandes centros. Este trabalho foi construído com a finalidade de compreender o perfil dos estudantes ingressos nestes cursos, analisando a visão do aluno quanto a estrutura didática disponível e as expectativas quanto ao final do curso. Com base nos resultados da pesquisa, acredita-se que o programa está alcançando bons resultados, mas há soluções pedagógicas que podem ser elaboradas e adotadas para mitigar os déficits na qualidade da formação recebida por futuros estudantes do projeto.

\section{Introdução}

A educação é um elemento fundamental no processo de desenvolvimento de um país (COESEUIL; SANTOS, 2000). O cenário da educação brasileira vem mudando nos últimos anos. (IPEA, 2014) mostra que desde 2000 os cursos de educação superior a distância no Brasil passaram a ter uma maior taxa de crescimento em relação aos cursos presenciais. Essas mudanças, propiciam um processo de aprendizagem em que professores e alunos, ao partilharem conhecimento em um ambiente virtual, em qualquer hora e lugar, fomentam uma construção do saber de forma cada vez mais flexível. Neste viés, o ensino, enriquecido por meio da versatilidade dos artifícios didáticos, torna possível o desenvolvimento da autonomia do aluno, o capacitando a aprender a aprender (RIBEIRO, 2013). "O espaço da escola virtual se apresenta através da estruturação de comunidades on-line na qual alunos e professores dialogam permanentemente, mediados pelo conhecimento" (KENSKI, 2003). No ambiente virtual, o acesso aos cursos, em qualquer local, compatível com a adaptabilidade de horários, viabiliza a maximização de adeptos a esta modalidade de ensino. Vive-se em uma era na qual as escolas virtuais ganham solidez para avançar no desenvolvimento e aprimoramento de competências. Diante desta realidade, Kenski (2003, p. 55) acredita que o conceito de escola e aprendizagem foi evoluído, definindo a escola virtual como 
"um ícone de um novo tempo tecnológico do espaço educativo".

Os cursos de educação na modalidade a distância $(\mathrm{EaD})$, ganharam espaço e força dentro do universo educacional, em seus segmentos pós-médio, superior e póssuperior, devido a potencialidades que as tecnologias contemporâneas proporcionaram ao acesso ao conhecimento. Ao mesmo tempo há uma crescente demanda de vagas especializadas que o mercado. Dados do (SENAI, 2012), indicam que até o ano de 2015 serão necessários 7,2 milhões de profissionais com nível técnico.

Com isso, a EaD progride no contexto nacional, uma vez que viabiliza e maximiza o acesso ao conhecimento. Como conseqüência do crescimento da $\mathrm{EaD}$, a legislação brasileira foi alterada nos últimos anos, recebendo definições que expressam as características e importância da EaD no processo de formação de capital humano para o progresso do parque de indústrias brasileiro. Por meio do Decreto $\mathrm{n}^{\circ} 5.622$, de 19 de dezembro de 2005 , no Art. $1^{\circ}$, a EaD recebeu a seguinte definição

modalidade educacional na qual a mediação didático-pedagógica nos processos
de ensino e aprendizagem ocorre com a utilizaçãa de meios e tecnologias de
informação e comunicação, com estudantes e professores desenvolvendo
atividades educativas em lugares ou tempos diversos (BRASIL, 2005).

De acordo com o Decreto ${ }^{\circ} 7.589$, de 26 de outubro de 2011, Art. $1^{\circ}$, a Rede eTec foi criada com a intenção de expandir "a educação profissional e tecnológica na modalidade de educação a distância" (BRASIL, 2011). A Rede e-Tec oferece à população de regiões distantes das zonas industriais, o acesso a uma educação profissionalizante gratuita e de qualidade na própria região suprindo as necessidades do mercado local. No Decreto $\mathrm{n}^{\mathrm{o}} 7.690$, de 2 de março de 2012, Art. $9^{\circ}$, destaca as atribuições da Secretaria de Educação Básica, no inciso VI: "formular, propor, planejar, avaliar e supervisionar políticas e programas de educação a distância, visando à universalização e democratização do acesso à informação, ao conhecimento e à educação básica".

A Rede e-Tec, uma das ações que integram o Programa Nacional de Acesso ao Ensino Técnico e Emprego (PRONATEC), prioriza a profissionalização de jovens e adultos de trabalhadores egressos do ensino médio ou do programa brasileiro de educação de jovens e adultos. Para Ribeiro (2013), a Rede e-Tec é compreendida como uma solução educacional com a missão de elevar a escolaridade e articular às demais ações da própria instituição, fortalecendo a viabilidade de permanência e assiduidade nos estudos. No relatório de prestação de contas da Secretaria de Educação Profissional e Tecnológica (SETEC), a Rede E-Tec é caracterizada como o programa que alarga as oportunidades de acesso aos jovens residentes nas periferias dos grandes centros e regiões isoladas, através do oferecimento de cursos técnicos na modalidade de educação à distância (MEC, 2013).

Estas ações surgem em um momento no qual o mercado precisa de uma grande quantidade de profissionais competentes para diversas áreas da indústria. O Mapa do Trabalho Industrial 2012, elaborado pelo Serviço Nacional de Aprendizagem Industrial (SENAI, 2012), aponta o Nordeste como a terceira região com maior carência de profissionais capacitados, atingindo o número de 854,50 mil, $11,9 \%$ do total da demanda por capacitação.

Diante desta realidade e da carente capacidade de formação que os Institutos Federais (IF) possuem, através do PRONATEC, foram criadas medidas para expandir, interiorizar e democratizar a oferta de cursos técnicos e de qualificação profissional. Por conseguinte, ações de expansão dos IFs vem crescendo, com o objetivo de criar 3.104.936 vagas até 2014, das quais 250.000 são destinadas para a Rede e-Tec. Atualmente existem 923 polos de EaD em atividade no Brasil. Para atender a demanda das novas vagas serão criados 600 novos polos entre 2013/ 2014 (FERES, 2013).

Esta pesquisa tem o objetivo de delinear o perfil dos alunos que buscam 
formação na modalidade a distância, a adequação do curso, mostrar a visão do aluno sobre o material didático disponível e as expectativas dos alunos quanto ao final do curso.

\section{Cursos Técnicos EaD e Presenciais}

Com a atual demanda do mercado são cobrados profissionais com diferencial. Exige-se pessoas que saibam ousar, pesquisar, inovar e empreender novos projetos, capazes de realizar trabalhos em grupos e individuais com autonomia, para progredir no mercado de trabalho da sociedade contemporânea (MORAN, 2013). Isto se reflete na Educação, pois para formar o profissional inovador, pesquisador e autônomo, é necessário oferecer ambientes de aprendizagem que desenvolvam e aprimorem tais práticas. Para alcançar este grau de autonomia, os jovens e adultos, recorrem aos cursos na modalidade presenciais ou a distância.

Neste contexto, a EaD ganhou espaço por permitir aos alunos a construção de novos conceitos em ambientes externos às salas de aulas convencionais. A proposta de ação pedagógica implementada pela $\mathrm{EaD}$, possibilita aos alunos, novos espaços de aprendizagem que fogem ao padrão tradicional do ensino presencial. Pelo viés da EaD, os alunos aprendem a ditar suas regras e exercer sua autonomia no processo de aprendizagem. Assim, a partir do momento no qual o aluno assume uma postura autônoma, ele se torna capaz de ditar as regras que ele seguirá, agindo de acordo com sua razão e respondendo diretamente por seu processo de aprendizagem (LOPES; FARIA, 2013).

Todas estas mudanças culminaram no entendimento dos alunos dos cursos técnicos da modalidade a distância, como indivíduos com a missão de quebrar as barreiras físicas, geográficas e temporais existentes no ensino presencial. Exercendo a autonomia de forma ética, e comprometida com o completo desenvolvimento de habilidades de aprendizagem autônoma.

Deste modo, o uso das Tecnologias da Informação e Comunicação (TIC) ganhou espaço na modalidade presencial e a distância, ofertando condições para um planejamento de estudo flexível capaz de consolidar ações de desenvolvimento integral no processo de aprendizagem a partir de recursos digitais em espaços distintos. Através dessa estrutura, o aluno da modalidade a distância, cria seu ritmo de acesso às atividades do ambiente virtual delineando os objetivos que pretendem atingir. Através do planejamento de estudo, o aluno aprende a cumprir os prazos estabelecidos pelo professor on-line, corroborando assim, com o desempenho acadêmico que é esperado por parte dos alunos (ZERBINI, 2007).

\section{Análise Qualitativa}

Como objeto de estudo dessa pesquisa, foram analisadas turmas iniciantes e concluintes de quatro cursos técnicos na modalidade $\mathrm{EaD}$ ofertados pelo IFPE: Manutenção e Suporte em Informática; Sistema de Energia Renovável; Manutenção Automotiva; Informática para Internet. Estes cursos são divididos em quatro módulos de seis meses de duração cada, totalizando dois anos de formação. Estes cursos possuem polos em quatro cidades: três polos no interior (Surubim, Garanhuns e Caruaru) e um na capital do estado de Pernambuco (Recife).

A análise realizada incluiu a coleta e análise de dados realizados a partir das respostas do questionário aplicado aos alunos. O questionário abrangeu 28 perguntas que contemplaram a identificação do aluno, a experiência profissional do aluno, a motivação na escolha do curso, a dedicação do aluno ao curso, a análise do curso, e o entendimento do mercado de trabalho e expectativas quando ao futuro profissional após finalização do curso. Cinco perguntas eram abertas podendo ser preenchidas pelo aluno livremente: 
- Qual a principal atividade profissional do aluno?

- Quais os motivos que levam os alunos a não conseguirem emprego na região do curso?

- Qual o entendimento do aluno sobre estar preparado para o mercado de trabalho ao final do curso? Indicaria curso?

- Quais motivos levam um aluno de EaD a ficar desmotivado?

Após a análise das respostas do questionário os dados foram relacionados durante a análise dos dados.

\subsection{Coleta dos dados}

Com o objetivo de fazer o levantamento das informações necessárias para a elaboração desta investigação, foi elaborado um questionário e enviado por email para 215 alunos regularmente matriculados nos cursos. Deste total, 138 alunos responderam ao questionário, compreendendo $64,2 \%$ do total pesquisado. Os dados colhidos estão disponíveis no endereço eletrônico: http://goo.gl/qyJn39; aonde são detalhados os resultados dos dados coletados dos questionários respondidos.

\subsection{Análise dos dados}

Após a coleta e compilação das respostas do questionário foram realizadas algumas análises com o objetivo de traçar o perfil dos alunos que buscam formação na modalidade a distância, a adequação do curso e da visão do aluno sobre o material didático disponível e as expectativas dos alunos quanto ao final do curso.

\subsubsection{Análise do Perfil do Aluno}

De acordo com a pesquisa realizada, $86,50 \%$ dos alunos são oriundos da zona urbana e $13,50 \%$ são da zona rural. O que nos revela um número expressivo de matrículas originárias em áreas que não são o foco do projeto da Rede e-Tec. Identificou-se que $82,96 \%$ dos alunos pesquisados têm uma renda familiar de até 3 salários mínimos e $80,74 \%$ dos alunos exerce atividade remunerada no mercado de trabalho.

Uma característica identificada no público pesquisado foi que $72 \%$ são homens jovens com idade entre 23 e 40 anos, sendo $26 \%$ até os 23 anos e $25 \%$ entre 23 e 27 anos e baixa escolaridade (76,11\% não possuem curso superior completo).

Como ponto de relevância para a escolha dos cursos técnicos a distância, foram considerados, principalmente, a frequência de encontros presenciais, sendo escolhido por $33,08 \%$ dos pesquisados, e a gratuidade do curso, com 27,82\%. Essas características possivelmente levaram $55,64 \%$ do público pesquisado a escolher cursos nos quais não possuíam nenhuma experiência. Apenas $25,95 \%$ dos alunos atua na área do curso escolhido. Dos $74,05 \%$ que ainda não atuam, $89 \%$ afirmaram que pretendem exercer atividades na área do curso escolhido.

Quanto ao tempo dedicado ao curso, 30,37\% dos respondentes investem até $5 \mathrm{~h}$ por semana de estudo, $40,74 \%$ investem entre $5 \mathrm{~h}$ e $10 \mathrm{~h}$ por semana, $28,15 \%$ entre $10 \mathrm{~h}$ e $20 \mathrm{~h}$ e $0,74 \%$ investem mais de $20 \mathrm{~h}$ de estudo por semana. Dados mostram que $89,63 \%$ do público pesquisado têm a facilidade de acessar os ambientes virtuais de aprendizagem no conforto de suas residências.

Deste modo, a procura por qualificação profissional leva muitos indivíduos a optarem por cursos técnicos EaD, por trata-se de uma modalidade de ensino com pouca frequência de encontros presenciais, mas que permite ao final do curso, a qualificação técnica nas áreas escolhidas pelos alunos. Esta procura pelos cursos da modalidade a distância também ocorre pelo fato, das TIC terem expandido para localidades distantes dos grandes centros, permitindo o acesso aos ambientes virtuais de aprendizagem nas 
próprias residências dos alunos.

\subsubsection{Adequação do Curso}

Mais da metade dos alunos $(77,22 \%)$ consideram o curso minimamente satisfatório ou regular. Foi possível notar também que os dados expõe um aumento na distância transacional ${ }^{1}$, considerando a estrutura do curso e a condução das disciplinas.

Os depoimentos a seguir de três alunos, exemplificam as lacunas que existem no processo, destacando a frustração que aconteceu na interação do curso

Aluno A: "A falta de respostas e de compromisso de muitos dos coordenadores...Um ensino que não se aprende não prende, não fascina, não motiva, em fim, não mexe com o interesse..."

Aluno B: "O fato de os professores nem sempre compreenderem o que queremos dizer. Isto causa mau entendimento em algumas ocasiões.”

\section{Aluno C: "Contato com os professores deixa a desejar."}

Em experimentos realizado com EaD e rede social educacional, Junior (2013) conclui que o ensino através destes recursos, viabiliza redução na distância transacional e motiva um maior nível de envolvimento entre o professor e os alunos. Isto por potencializar a aprendizagem colaborativa entre as partes, professor e aluno, fomentando novas formas sócio-interacionistas.

Com o amadurecimento da prática da $\mathrm{EaD}$, a comunidade científica foi compreendendo que o desafio não é a utilização de novas tecnologias para reproduzir os sistemas tradicionais de ensino, mas sim fomentar novos espaços de aprendizagem, proporcionando melhorias para professores e alunos, e por conseguinte melhorar a qualidade da educação (PERRIS, 2013).

Neste aspecto, foi detectado esta lacuna no estado atual do projeto, não existindo aprendizagem promovidas através de esforços colaborativos. Este cenário minimiza a ocorrência de interação entre todos os envolvidos, descaracterizando o aprendizado colaborativo tão defendido na comunidade científica (Luz, 2013; Dias Júnior, 2012), e por conseguinte, deixando escapar oportunidades de potencialização da partilha, comunicação e colaboração entre todos, favorecendo e melhorando o desempenho dos discentes.

\subsubsection{Material Didático}

Quanto ao material fornecido a necessidade do curso apenas $30,47 \%$ consideraram que o material atende a necessidade do curso. Dos 69,53\% que não consideram o material completamente adequado, $95 \%$ faz uso da internet para complementar o material recebido.

\subsubsection{Expectativas dos Alunos quanto a Conclusão do Curso}

$71,32 \%$ dos alunos de EaD afirmaram que a necessidade de conclusão do curso é imediata, desses $89,13 \%$ não possuem terceiro grau completo. O que evidencia que os alunos buscaram a formação técnica nos cursos da modalidade a distância para obter uma formação qualificada, capaz de promover sua inserção no mercado especificamente na área escolhida.

Nos estudos desenvolvido por Alencar (2013), uma conclusão fundamental para conseguir unir o interesse do aluno, é fomentar uma solução educacional atrelada à necessidade pessoal de cada envolvido no processo. Um dos resultados observados na pesquisa realizada, aponta que a escolha do curso técnico $\mathrm{EaD}$ decorra da baixa

1 O conceito de distância transacional traça a relação entre professor e alunos quando separados geograficamente, e foi construído baseado na estrutura do curso, na interação/diálogo entre os envolvidos e no nível de autonomia dos alunos no curso (MOORE, 2002; TORI, 2008). 
necessidade de encontros presenciais, um escolha realizada por 32.8\% (Figura 1) dos pesquisados. Isto demonstra uma forte tendência da buscar por capacitação em tempo alternativo, sem comprometer as demais atividades.
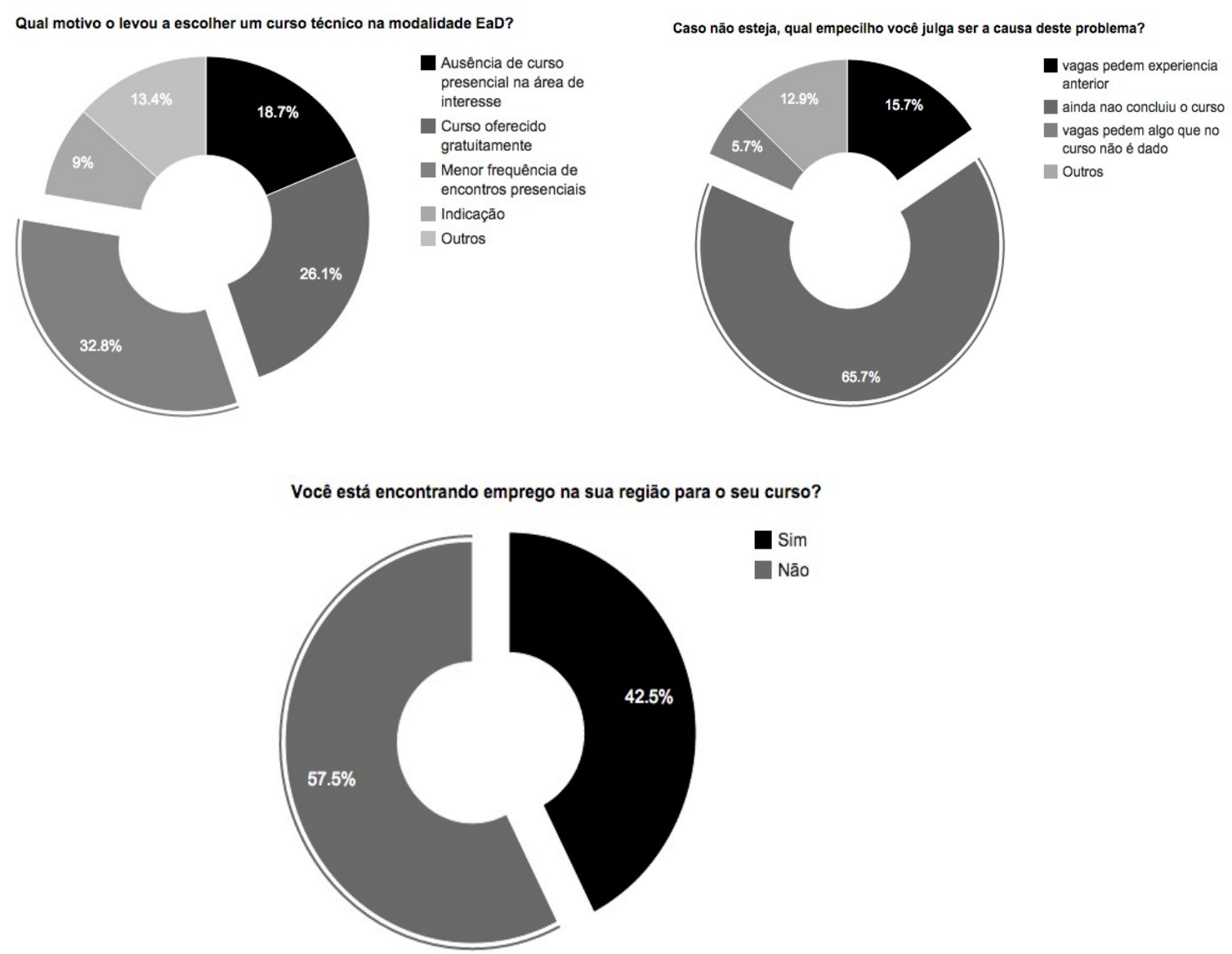

Figura 1. Gráficos relativos as informações sobre a perspectiva do mercado de trabalho

Quando questionado sobre o estado de oferta de vagas para sua localidade e adjacências, notou-se uma taxa singela de aproveitamento dos estudantes, sendo um fator indicativo do baixo preparo da localidade para absolver os profissionais formados nos cursos técnicos, o que reflete no fato de $57,50 \%$ do público pesquisado afirmar que não encontra trabalho em sua região na área do curso escolhido.

$\mathrm{O}$ processo de inserção dos alunos recém-formados no mercado de trabalho exige da região uma demanda de vagas capaz de absorver os profissionais, evitando o deslocamento destes para outras localidades. Além disso, algumas empresas cobram experiências anteriores na função para o candidato assumir a vaga.

\section{Conclusões}

O Governo Federal, diante da necessidade de formação de profissionais para atender à indústria, vem fazendo elevados investimento na educação técnica, democratizando o acesso à capacitação. As políticas e medidas educacionais realmente cumpriram sua missão, quanto estas suprirem a carência formativa que os cursos possuem atualmente. Uma medida que venha trazer auxílio para estas limitações é a utilização de soluções pedagógicas condizentes com as características regionais dos alunos, minimizando a evasão e potencializando rendimentos maiores na formação destes.

Nesta investigação, aspectos regionais, que compõe a realidade vivida pelos 
estudantes destes cursos, foram coletadas e analisadas. Notou-se que os estudantes possuem claro descontentamento com o processo educacional adotado pelo programa, não auxiliando na construção de novas relações sociais, e assim, mantendo a distância transacional na prática docente. Os cursos de EaD de forma geral vem conseguindo atingir pessoas que não possuíam acesso a educação complementar. Existe também uma grande expectativa dos alunos quanto a finalização do curso. Foram identificados alguns pontos de melhoria no programa com base nos dados levantados.

Um dos pontos levantados é relativo ao acesso à internet na própria residência. Por isso a expansão do acesso as TIC é um fator bastante relevante para uma maior abrangência de alunos. Outro fator observado foi a necessidade de investimento no material didático. A maioria dos alunos é descontente quanto ao material didático oferecido.

Um outro tópico que precisa ser trabalhado é a necessidade do programa atingir alunos da zona rural pois hoje a maior parte dos alunos é oriunda de zonas urbanas.

Por fim é necessário realizar uma ligação entre a indústria e os cursos de EaD proporcionando oportunidades de trabalho para os alunos do curso. Pretende-se expandir esse estudo, ao realizar questionamentos mais aprofundados das expectativas dos estudantes para a carreira, bem como mapear a realidade da indústria local, e assim, aferir as necessidades de ambos, para então, construir modelos educacionais que unam os dois interesses. Estas medidas buscaram atender a missão cerne dos programas de educação profissional e tecnológica, da interiorização e a fixação dos profissionais que venham a concluir o curso em suas respectivas localidades.

\section{Referencias}

ALENCAR, G. D.; FARIAS, C. B. A.; SILVA, J. F. G.; QUEIROZ, A. A. L. ; PASSOS, L. M. S. (2013) "FaceEduc: Uma Adaptação Visual do Moodle Baseada na Interface e Mecanismos de Interação do Facebook". In: II Congresso Brasileiro de Informática na Educação, XXIV Simpósio Brasileiro de Informática na Educação.

ALVES, João Roberto Moreira. A história da EAD no Brasil. In: LITTO, Fredric Michael; FORMIGA, Manuel Marcos Marciel. Educação a distância: o estado da arte. São Paulo: Pearson Education do Brasil, 2009.

BRASIL. Decreto N. ${ }^{\circ}$ 2.494, de 10 de Fevereiro de 1998. Regulamenta o Art. 80 da LDB - Lei n. ${ }^{\circ}$ 9.394/96. Diário Oficial da União. Poder Executivo, Brasília, 10 fev. 1998. Disponível em: <http://portal.mec.gov.br/seed/arquivos/pdf/tvescola/ leis/D2494.pdf>. Acesso em: 28 abr. 2014.

BRASIL. Decreto N. ${ }^{\circ}$ 5.622, de 19 de Dezembro de 2005. Regulamenta a EAD. Diário Oficial da União. Poder Executivo, Brasília, 20 dez. 2005. Disponível em: $<$ http://www.planalto.gov.br/ccivil_03/_ato2004-2006/2005/Decreto/D5622.htm>. Acesso em: 14 de maio de 2014.

BRASIL. Decreto N. ${ }^{\circ}$ 7.589, de 26 de Outubro de 2011. Institui a Rede e-Tec Brasil. Diário Oficial da União. Poder Executivo, Brasília, 27 out. 2011. Disponível em: $<$ http://www.planalto.gov.br/ccivil_03/_Ato2011-2014/2011/ Decreto/D7589.htm>. Acesso em: 13 de maio de 2014.

COESEUIL, C. H.; SANTOS, D. D. Decisões críticas em idades críticas: a escolha dos jovens entre estudo e trabalho em seis países da América Latina, Campinas-SP, 2000. 
DIAS JÚNIOR, M.V.; PARAGUAÇU, F. (2012) Uma contribuição para o uso de atividades educativas utilizando aprendizagem colaborativa via TV Digital Interativa e Web. In: I Congresso Brasileiro de Informática na Educação; XXIII Simpósio Brasileiro de Informática na Educação.

FERES, M. PRONATEC Oferta de Cursos Técnicos Subsequentes-Desafios e Realizações. Seminário ABMES. 2013. Disponível em: http:// www. a b m e s . o r g . b r / a b m e s/public/a r q u i o s/d o c u m e n t o s / apresentacao_seminario_julho_pronatec_marcelo_feres.pdf. Acesso em: abril 2014

FREIRE, Paulo. Pedagogia da autonomia: saberes necessários à prática educativa. 25 . ed. São Paulo: Paz e Terra, 1996.

GROSSI, M. G. R.; NUNES, R. C. Perfil sócio-demográfico dos alunos evadidos do curso técnico a distância em Segurança do Trabalho do Polo Cabo Frio Instituto Federal Fluminense: Um estudo de caso. 19 CIAED - Congresso Internacional ABED de Educação a Distância, Salvador-BA, 2013.

IPEA, Evolução do acesso de jovens à educação superior no Brasil. 2014.

JUNIOR, E. V. B.; GOMES, A. S.; SOUZA, F. V. C. ; ALVES, S. V. L. Análise da prática docente com rede social educativa na disciplina de Programação Orientada a Objeto. In: II Congresso Brasileiro de Informática na Educação; XIX Workshop de Informática na Escola, 2013.

KENSKI, Vania Moreira. Tecnologia e ensino presencial e a distância. 9. ed. Campinas, SP: Papirus, 2003.

LITTO, Frederic M.; FORMIGA, Marcos. Educação à distância: o estado da arte. São Paulo: Prentice Hall, 2009.

LOPES, Luís Fernando; FARIA, Adriano Antônio. O que e o quem da EAD: história e fundamentos. Curitiba: Ibpex, 2013.

MAIA, Carmem; MATTAR, João. ABC da EaD. São Paulo: Pearson Prentice Hall, 2007.

MEC. Relatório de Gestão da Secretaria de Educação Profissional e Tecnológica (SETEC). Disponível em: http://portal.mec.gov.br/index.php? option $=$ com_docman\&task $=$ doc_download\&gid $=14259 \&$ Itemid $=$. Acesso em: abril 2014.

MOORE, M. (2002). Teoria da Distância Transacional. Disponível em: http://www.abed.org.br/revistacientifica/revista_pdf_doc/2002_teoria_distancia_trans acional_michael_moore.pdf. Acesso em: abril 2014.

MORAN, José Manuel. A Educação que desejamos: novos desafios e como chegar 'á. Campinas: Papirus, 2013.

PERRIS, P. A. R.; RODRIGUES, R. L.; GOMES, A. S. Concepção de ferramentas de percepção, representando dados do fluxo de atividades discentes em ambiente colaborativo de aprendizagem. In: II Congresso Brasileiro de Informática na 
Educação; XXIV Simpósio Brasileiro de Informática na Educação, 2013.

RIBEIRO, L.O.M.; Antunes, V.M. A diversidade na EaD: um olhar sobre a rede E-TEC Brasil. 19 CIAED - Congresso Internacional ABED de Educação a Distância, Salvador -BA, 2013.

SENAI. Indústria precisará de 7,2 milhões de técnicos até 2015. Disponível em: http://www.senaimt.com.br/site/mostra.php?noticia=8"54. Acesso em: abril 2014.

TORI, R. (2008). Cursos híbridos ou blended learning. In: Educação a distância: O Estado da Arte, Ed. São Paulo: PEARSON.

ZERBINI, T. Avaliação do Treinamento em Curso a Distância. Brasília, 2007. 321p. Tese (Doutorado em Psicologia) - Instituto de Psicologia, Universidade de Brasília, Brasília - DF. 